\title{
High HIV/STI Test Acceptance Through a Behavioral Health Encounter in Latino Immigrants with Substance Use and Mental Health Problems
}

\author{
Julie H. Levison ${ }^{1,2} \circledast$ - Margarita Alegría ${ }^{1,6,7} \cdot$ Ye Wang $^{7} \cdot$ Sheri L. Markle $^{7} \cdot$ Larmiar Fuentes $^{7} \cdot$ Dianna L. Mejia $^{2}$. \\ Andrew Tarbox ${ }^{2} \cdot$ Lucía Albarracín García $^{3} \cdot$ Lucía Cellerino $^{4} \cdot$ Nabila El-Bassel $^{5}$
}

Published online: 8 February 2019

๑) Springer Science+Business Media, LLC, part of Springer Nature 2019

\begin{abstract}
Latino immigrants with substance use and mental health problems are at risk for undiagnosed HIV and sexually transmitted infections (STIs). Participants in a randomized control trial were recruited in Boston, USA and Madrid and Barcelona, Spain. Eligibility criteria were Latino self-identification, age 18-70, elevated substance use and mental health symptoms, and not currently in substance or mental health care. A multinomial logistic regression examined predictors of HIV/STI testing decline and lost to follow-up (LTFU) prior to testing compared with acceptance. Of 341 participants, 74\% accepted testing, $4 \%$ declined, and $22 \%$ were LTFU. The odds of LTFU were higher in those with high concern for HIV and those whose main partner had done HIV testing. Age $\geq 35$ years, females, higher education, and higher report of discrimination lowered the odds of LTFU. Delivery of HIV/STI testing through community agencies and outreach could overcome barriers to HIV/STI diagnosis in this population of Latinos.

Clinical Trial Number: NCT02038855
\end{abstract}

Keywords HIV $\cdot$ Sexually transmitted infections $\cdot$ Testing $\cdot$ Latinos $\cdot$ Mental health $\cdot$ Substance use

\section{Resumen}

Los inmigrantes de origen latino con problemas de uso de sustancias y salud mental presentan un mayor riesgo de no ser diagnosticados del VIH y de las infecciones de transmisión sexual (ITS). Los participantes de este ensayo aleatorio controlado fueron reclutados en Boston, Estados Unidos y en Madrid y Barcelona, España. Los criterios de elegibilidad incluían autoidentificarse como Latino, tener edad entre 18 y 70 años, síntomas elevados de uso de sustancias y un trastorno psicológico, y no estar recibiendo ningún tratamiento para estas condiciones. Una regresión logística multinomial examinó los predictores de la disminución del test del/las VIH/ITS y pérdida de seguimiento (PDS) antes de ofrecer el test del/las VIH/ITS comparándolo con los que aceptaron realizar el test y mantenerse en tratamiento. De los 341 participantes, un $74 \%$ aceptó realizarse las pruebas, un $4 \%$ las rechazó, y un $22 \%$ fue PDS. La probabilidad de PDS fue mayor en aquellos con alta preocupación por el VIH y en aquellos cuya pareja principal se había realizado el test del VIH. Tener más de $\geq 35$ años, ser mujer, alcanzar la educación superior, e indicar un alto nivel de discriminación percibida fueron factores relacionados con la reducción de la probabilidad de PDS. La realización del test del/las VIH/ITS a través de las agencias comunitarias y sus actividades de captación podrían superar las barreras del diagnóstico de VIH/ITS en esta población de Latinos.

Julie H. Levison

jlevison@partners.org

1 Department of Medicine, Massachusetts General Hospital of Harvard Medical School, Boston, USA

2 Division of General Internal Medicine, Massachusetts General Hospital, Boston, USA

3 Department of Psychiatry, Hospital Universitario Fundación Jiménez Diaz, Madrid, Spain
4 Department of Psychiatry, Vall d'Hebron University Hospital, Barcelona, Spain

5 Columbia School of Social Work, New York, USA

6 Department of Psychiatry, Massachusetts General Hospital of Harvard Medical School, Boston, USA

7 Disparities Research Unit, Department of Medicine, Massachusetts General Hospital, Boston, USA 


\section{Introduction}

A sizeable portion of HIV-infected persons $(\sim 15 \%)$ are unaware of their HIV serostatus in the US and Spain [1, 2]. Men who have sex with men and persons who inject drugs are at greater risk for unknown HIV serostatus [1], which is associated with high-risk behaviors in Latinos and other ethnic groups [3-5]. Undetected HIV infection undermines HIV prevention and treatment goals to curb the epidemic and improve treatment outcomes [6].

In 2015, there were nearly 250 million international immigrants of whom 32.5 million were from Latin America and the Caribbean region [7, 8]. Latino immigrants are a sizeable portion of the population in US and Spain. In the US, Latinos represent 56.5 million persons of whom $34 \%$ are non-US born [9]. In Spain, there are 4.6 million immigrants with a rising number of individuals from Central and South America in recent years [10,11]. The UNAIDS considers immigrants a particularly vulnerable population to HIV infection [12]. In Spain, the Ministry of Health defines immigrants as a key population at risk for HIV infection as immigrants represent $32 \%$ of new HIV infections [13]. The US Centers for Disease Control (CDC) identifies Latinos as a key population in the HIV epidemic as they comprise $18 \%$ of the general US population and 24\% of new HIV infections [14].

Many of the characteristics associated with immigration track with risk factors for sexually transmitted infections (STIs), including HIV. Economic disruption, psychological stress, population mobility and displacement, trauma and physical violence, and military activity associated with migration are risk factors for HIV transmission [15, 16]. Untreated substance use and mental health problems can affect the perceived risk for HIV acquisition and promote high-risk behaviors such as sexual concurrency, unprotected anal intercourse, and injection drug use (IDU) [17-19].

Latinos, particularly foreign-born, experience delays in HIV diagnosis due to a number of individual and systemlevel factors [20-23]. Social isolation, and "double discrimination" of HIV infection and immigrant status can delay HIV testing in Latino immigrants [24-27]. Furthermore, fear of unjust treatment, perceived discrimination, and medical mistrust are barriers to HIV services in the US and abroad [3, 28, 29]. Cultural factors, such as gender roles [30], degree of acculturation [31, 32], and risk taking behaviors that are a product of acculturative stress [33, 34], can impair the perceived need for HIV and STI testing. Mental health and substance use problems can also decrease the perceived value of HIV testing $[35,36]$. Characteristics that predict HIV testing in Latinos with co-occurring mental health and substance use problems remains poorly understood.
Since migration can serve as a risk factor for HIV and delayed HIV testing is more common in foreign-born persons, targeting HIV testing in Latino immigrants could uncover an important population who could benefit from HIV prevention and treatment services. Furthermore, including HIV testing in mental health or community settings may importantly broaden the paradigm of HIV testing to reach key populations [37].

Our study had two objectives: (1) to assess HIV/STI test acceptance within a behavioral health setting for a population with historically delayed HIV diagnosis and (2) to understand factors that predict HIV/STI test decline and loss to follow-up (LTFU) to inform more tailored testing interventions. We hypothesized that offering HIV/STI testing by bicultural, bilingual staff and through a behavioral health encounter would facilitate test acceptance in Latino immigrants with substance use and mental health problems.

\section{Methods}

\section{Study Setting and Population}

The study was conducted from September 2014 to February 2017 at three large health systems in Boston, USA, Madrid, and Barcelona, Spain. These sites were selected due to their high density of Latino immigrants and their experience collaborating on behavioral health interventions for Latinos [38-40]. Study referral sources were primary care and HIV clinics, emergency rooms, community-based agencies, and peers or family. All participants were self-reported Latinos, Spanish or English speaking, and between the ages of 18-70 years. Since the majority of participants were foreignborn Latinos, they are referred to here as Latino immigrants.

Eligibile participants screened positive to both substance use and mental health problems as determined by the AC-OK screener [41, 42]. Participants needed to score positive in at least two items of the mental health and two items in the substance use subscales. The Spanish-language version of the AC-OK had good concordance (using the current cut-offs) with drug misuse (DAST-10 score $\geq 3$ ) and alcohol misuse (AUDIT-C score $\geq 3$ ) [41].

Exclusion criteria were evidence of any of the following: (1) recent (last 3 months) or upcoming (in the next month) specialist appointment for mental health or substance use treatment; (2) lack of capacity to consent to the study (as measured by a validated screener); and (3) current suicidal risk or risk of harm to others [43]. Self-report of current use of psychotropic medications was not an exclusion. 


\section{HIV/STI Testing Procedures}

HIV/STI testing occurred through a randomized trial of a brief behavioral intervention called "Integrated Intervention for Dual Problems and Early Action" (IIDEA), a part of the International Latino Research Partnership (NIDA R01DA034952). The trial was delivered in primary care settings to address mental health, substance use and prevention of HIV/STIs, in particular to test the effectiveness of this intervention on depression, anxiety, post-traumatic stress disorder symptomatology, and drug and alcohol use [44]. In the IIDEA arm, participants received an 8-10 session program of cognitive behavioral therapy and mindfulness treatment as well as two sessions focused on HIV and STIs prevention as adapted for Latino immigrants from the CONNECT and RESPECT interventions [45, 46]. In enhanced usual care, participants received five telephone calls from study staff over the 6 month period to assess for any deterioration of mental health and, if necessary, link the participant to services.

HIV/STI testing was offered in both intervention and usual care conditions. In the intervention, study clinicians offered HIV/STI testing at week 7 during an HIV-focused session. In the usual care condition, study staff offered HIV/ STI testing at week 6 study calls. In patients with medical record documentation of HIV infection, study staff offered STI testing alone. Participants who tested positive for HIV infection, $C$. trachomatis, or $N$. gonorrhea were linked to services for confirmatory testing and treatment. Those who tested negative were encouraged to repeat HIV testing in the future and were provided information. At study conclusion, staff re-contacted participants who had not received HIV/ STI testing. Participants were compensated with a $\$ 25 / 30 €$ gift card for assessments and up to a $\$ 50 / 40 €$ gift card for transportation costs and completing HIV/STI testing.

HIV testing was offered as an oral swab point-of-care test with OraQuick (OraSure Technologies, Inc, Bethlehem, PA) and results were available in $20 \mathrm{~min}$. N. gonorrhea and C. trachomatis testing was performed by urine nucleic acid amplification test (NAAT) (Choplogic/Gen-Probe Inc., San Diego, CA). Study staff collected urine specimens from participants and samples were retrieved by a local standardized laboratory. Results were available in three to seven days of specimen receipt. Within 7 days of receiveing NAAT results, study staff provided participants an appointment for result notification.

\section{Measurements}

All participants took part in a baseline assessment measuring potential predictors of HIV/STI test acceptance (e.g. socio-demographic, access to services, mental health, migration and culture, and HIV/STI risk factors). Mental health problems, as reported in the baseline assessment, were major depression (PHQ-9 $\geq 10$ ), anxiety (GAD-7 $\geq 10$ ) and trauma (PCL-5 $\geq 33$ ).

Depressive symptoms were measured with the 9-item Patient Health Questionnaire (PHQ-9). Items were summed. Higher scores reflected greater severity of depression (outcome range $0-27)(\alpha=0.85)$ [47].

The Generalized Anxiety Disorder (GAD-7) scale has seven questions. Responses were summed. Higher scores represented more severe symptoms (outcome range 0-21) $(\alpha=0.86)$ [48].

The 20-item Post-Traumatic Stress Disorder Checklist (PCL-5) measured PTSD based on DSM-V criteria (outcome range $0-80)(\alpha=0.94)$ [49].

Substance abuse was measured with the 10-item Drug Abuse Screening Test-10 (DAST-10). "Yes" items were added (outcome range $0-10)(\alpha=0.87)$ [50]. Harmful or hazardous drinking was measured by a score of 3 or higher on the 3-item alcohol use disorders identification test (AUDIT-C) $(\alpha=0.78)$ [51].

The Benzodiazepine Dependence Questionnaire (BDEPQ) measured experiences with benzodiazepenes (outcome range $0-27)(\alpha=0.90)$ [52]. We chose 10 items with higher loading and face validity in Latinos. Higher scores reflected greater severity of benzodiazepene dependence.

We measured factors related to migration and culture. The 10-item brief trauma questionnaire assessed traumatic exposure according to DSM-IV [53, 54]. Two questions queried citizenship and residency status, which we grouped into three categories: citizen, undocumented immigrant, and documented immigrant. Sense of belonging was measured with one item from the Family/Culture Stress subscale of the Hispanic Stress Inventory (HSI): "Do you feel like you do not belong in either your Latin country or the US/Spain?" [55]. Health literacy was measured with three items from the Health Literacy Screening Questionnaire and one item from the Single Item Literacy Screener (outcome range 3-5) $(\alpha=0.80)$ [56, 57]. Higher scores signified higher health literacy.

Routine experiences of discrimination were measured with the 9-item Everyday Discrimination Scale [58]. Responses were reverse coded and summed (outcome range 9-45) $(\alpha=0.83)$. Higher scores reflected more severe everyday discrimination.

Acculturative stress was measured with 3 questions on a Likert-scale: "You feel rejected by other people because you are Latino?"; "You've had problems making friends, because you don't know enough of their language, customs or ways of interacting?"; and "You haven't been treated well, because you don't speak their language well or speak with an accent?'. Responses were summed (outcome range 0 to 9) $(\alpha=0.82)$. Higher responses signified more acculturative stress. Family conflict was measured with 4 items from the 
Family/Culture Stress subscale of the HSI (outcome range $0-10)(\alpha=0.67)[59,60]$.

HIV risk behaviors were measured with items from the Data Harmonization instruments employed by the National Institute on Drug Abuse (NIDA) [61-63].

\section{Data Analysis}

The primary outcome was uptake of either HIV or STI testing. We hypothesized that the predictors of HIV and STI testing would be similar since these tests were offered simultaneously. We were interested in comparing differences between three groups of participants: test accepters, test decliners, and those LTFU. The LTFU group were individuals who had dropped-out of the study due to inability for a study staff member to reach them. Therefore, these participants were unable to receive HIV/STI testing. The primary analysis included all enrolled individuals. We included covariates based on their reported relevance described in the literature as associated with health care utilization and HIV/ STI risk in Latinos.

To assess risk behavior, we selected potential predictors of chlamydia, gonorrhea, and HIV infection from the published literature [64-66]. These variables were concern for acquiring HIV, prior HIV testing, number of sex partners in the past year, history of HIV testing in the main sexual partner, lifetime history of IDU in the participant and his/ her main sex partner, history of sex without a condom in the main or casual partner in the past year, history of anal sex without a condom in the main or casual partner in the past year, lifetime history of sex with a commercial sex worker, and lifetime history of a STI.

We assessed differences in the groups (test accepters, decliners, and those LTFU), comparing proportions and means (with standard deviations [SD]), using Chi square and t-tests, respectively, for significance. Multinomial logistic regression controlled for covariates to evaluate factors associated with test acceptance as the reference category. A multinomial model enabled a complete description of the observations by accounting for those participants who were LTFU [67]. We then added fixed effects to assess for differences in outcomes by city of recruitment. To create a parsimonious model, we examined the distribution of potential predictors. We excluded variables that led to perfect prediction of test decline due to the small sample size in this group [68]. Composite mental health (PHQ-9, GAD-7, and PCL-5) and substance use (DAST-10, AUDIT-C, and BDEPQ) variables were created to avoid multi-collinearity. To avoid collinearity between study site and recruitment site, we combined the participants recruited from the emergency room with participants recruited from the primary care setting. This re-categorization of recruitment site allowed us to examine recruitment for HIV/STI testing from healthcare settings versus community agencies. We aggregated the corresponding measures and standardized them to a scale of 0-100. Backward elimination removed variables that were not statistically significant at $p>0.25$. Results were expressed as odds ratios (OR) with $95 \%$ confidence intervals (CI) and computed by Stata software [69].

\section{Informed Consent}

This study was approved by institutional review boards in Boston, MA, Madrid, and Barcelona, Spain. A Certificate of Confidentiality was implemented from NIDA for the USbased participants. Study staff met with potential participants in a private area of the clinic to administer informed consent. The consent form described key elements of the protocol, including that study staff would offer HIV/STI testing and, in Boston, that the Certificate of Confidentiality protected participants from forced disclosure of identifiable research information. During the consent process, study staff also obtained patient consent to contact emergency service providers should the participant endorse harmful thoughts or behaviors.

\section{Results}

\section{Characteristics of HIV/STI Test Acceptance, Decline, and LTFU in Latino Immigrants}

Three hundred forty-one individuals were enrolled and offered HIV/STI testing, of whom $74 \%(\mathrm{n}=252)$ accepted, $4 \%(\mathrm{n}=15)$ declined, and $22 \%(\mathrm{n}=74)$ were LTFU (Table 1). Participants recruited from Barcelona were 52\% $(n=176)$, from Madrid were 25\% $(n=84)$, and from Boston were $24 \%(n=81)$ of the study population. The significant clinical variables were major depression and alcohol abuse. The mean PHQ-9 score was $10.92(\mathrm{SD} \pm 5.73)$ and mean AUDIT-C score was $5.40(\mathrm{SD} \pm 3.46)$. Past history of trauma was reported in 95\% $(n=324)$ and the mean PCL-5 score was $26.47(\mathrm{SD} \pm 17.20)$.

In unadjusted analyses, those who declined HIV/STI testing or were LTFU were more likely to be younger (age 18-34 years) than those who accepted testing $(\mathrm{p}=0.003)$. In those who accepted testing, $52 \%(\mathrm{n}=132)$ were age 18-34 years, compared with $60 \%(n=9)$ of those who declined and $74 \%(n=55)$ of those LTFU. The distribution of country of origin differed by testing category $(\mathrm{p}=0.003)$. In those who accepted testing, $6 \%(n=16)$ were from the U.S., $14 \%(\mathrm{n}=36)$ were from Central America, and 68\% $(n=172)$ were from South America. Of the 15 participants that declined testing, $20 \%(\mathrm{n}=3)$ were Latinos from the U.S., $20 \%(\mathrm{n}=3)$ were from Central America, and $40 \%$ $(n=6)$ were from South America. In those who were LTFU, 
Table 1 Characteristics of participants $(n=341)$ in a retrospective study of HIV/STI test acceptance in Latino immigrants with co-occurring substance abuse and mental health disorders enrolled in a bi-national randomized behavioral trial

\begin{tabular}{|c|c|c|c|c|c|c|c|c|c|}
\hline \multirow[t]{2}{*}{ Charateristics } & \multicolumn{2}{|c|}{ Total $(n=341)$} & \multicolumn{2}{|c|}{$\begin{array}{l}\text { Accept HIV/STI } \\
\text { Test }(\mathrm{n}=252)\end{array}$} & \multicolumn{2}{|c|}{$\begin{array}{l}\text { Decline HIV/STI } \\
\text { Test }(n=15)\end{array}$} & \multicolumn{2}{|c|}{$\begin{array}{l}\text { Lost to Follow- } \\
\text { Up }(n=74)\end{array}$} & \multirow[b]{2}{*}{$\mathrm{p}$ value } \\
\hline & $\mathrm{N}$ & $\%$ & $\mathrm{~N}$ & $\%$ & $\mathrm{~N}$ & $\%$ & $\mathrm{~N}$ & $\%$ & \\
\hline \multicolumn{10}{|l|}{ Socio-demographic } \\
\hline \multicolumn{10}{|l|}{ Age (years) } \\
\hline $18-34$ & 196 & 58 & 132 & 52 & 9 & 60 & 55 & 74 & \multirow[t]{3}{*}{0.003} \\
\hline $35-49$ & 96 & 28 & 75 & 30 & 6 & 40 & 15 & 20 & \\
\hline $50+$ & 49 & 14 & 45 & 18 & 0 & 0 & 4 & 5 & \\
\hline \multicolumn{10}{|l|}{ Gender } \\
\hline Male & 167 & 49 & 115 & 46 & 7 & 47 & 45 & 61 & \multirow[t]{2}{*}{0.070} \\
\hline Female & 174 & 51 & 137 & 54 & 8 & 53 & 29 & 39 & \\
\hline \multicolumn{10}{|l|}{ Race } \\
\hline White & 60 & 18 & 49 & 19 & 1 & 6.7 & 10 & 14 & \multirow[t]{5}{*}{0.226} \\
\hline Black & 18 & 5 & 15 & 6 & 1 & 6.7 & 2 & 3 & \\
\hline Indigenous/Native American & 26 & 8 & 22 & 9 & 1 & 6.7 & 3 & 4 & \\
\hline Hispanic/Latino/Caribbean & 35 & 10 & 27 & 11 & 3 & 20 & 5 & 7 & \\
\hline Mixed & 201 & 59 & 138 & 55 & 9 & 60 & 54 & 73 & \\
\hline \multicolumn{10}{|l|}{ Country of origin } \\
\hline United States & 21 & 6 & 16 & 6 & 3 & 20 & 2 & 3 & \multirow[t]{5}{*}{0.003} \\
\hline Spain & 2 & 1 & 1 & 1 & 1 & 7 & 0 & 0 & \\
\hline Central America & 45 & 13 & 36 & 14 & 3 & 20 & 6 & 8 & \\
\hline South America & 239 & 70 & 172 & 68 & 6 & 40 & 61 & 82 & \\
\hline Caribbean & 34 & 10 & 27 & 11 & 2 & 13 & 5 & 7 & \\
\hline \multicolumn{10}{|l|}{ Study site } \\
\hline Boston & 81 & 24 & 64 & 25 & 6 & 40 & 11 & 15 & \multirow[t]{3}{*}{0.003} \\
\hline Madrid & 84 & 25 & 71 & 28 & 2 & 13 & 11 & 15 & \\
\hline Barcelona & 176 & 52 & 117 & 46 & 7 & 47 & 52 & 70 & \\
\hline \multicolumn{10}{|l|}{ Educational status } \\
\hline Less than high school & 131 & 38 & 91 & 36 & 7 & 47 & 33 & 45 & \multirow[t]{3}{*}{0.006} \\
\hline High school diploma and vocational & 144 & 42 & 100 & 40 & 7 & 47 & 37 & 50 & \\
\hline College degree and higher & 66 & 19 & 61 & 24 & 1 & 7 & 4 & 5 & \\
\hline \multicolumn{10}{|l|}{ Access to services } \\
\hline \multicolumn{10}{|l|}{ Insurance status } \\
\hline No insurance & 22 & 7 & 19 & 8 & 0 & 0 & 3 & 4 & 0.335 \\
\hline Yes with insurance & 318 & 92 & 233 & 93 & 15 & 100 & 70 & 95 & \\
\hline Unknown/no response & 1 & 0 & 0 & 0 & 0 & 0 & 1 & 1 & \\
\hline Recruitment site & & & & & & & & & \\
\hline Primary care & 148 & 43 & 106 & 42 & 8 & 53 & 34 & 46 & 0.848 \\
\hline Community agency/referral & 174 & 51 & 131 & 52 & 6 & 40 & 37 & 50 & \\
\hline Emergency room & 19 & 6 & 15 & 6 & 1 & 7 & 3 & 4 & \\
\hline & Mean & SD & Mean & SD & Mean & SD & Mean & SD & $\mathrm{p}$ value \\
\hline Mental health & & & & & & & & & \\
\hline Depression (PHQ-9) (0-27) & 10.92 & 5.73 & 11.22 & 5.71 & 11.07 & 6.75 & 9.86 & 5.53 & 0.200 \\
\hline Generalized anxiety (GAD-7) (0-21) & 8.59 & 5.07 & 8.85 & 5.07 & 8.27 & 5.70 & 7.78 & 4.91 & 0.277 \\
\hline PTSD (PCL-5) (0-80) & 26.47 & 17.20 & 26.82 & 17.06 & 28.53 & 19.51 & 24.85 & 17.32 & 0.615 \\
\hline Substance use disorders (DAST-10) $(0-10)$ & 1.36 & 2.30 & 1.31 & 2.27 & 1.20 & 1.90 & 1.60 & 2.50 & 0.601 \\
\hline Alcohol abuse (AUDIT-C) $(0-12)$ & 5.40 & 3.46 & 5.36 & 3.50 & 5.33 & 3.24 & 5.55 & 3.43 & 0.911 \\
\hline Benzodiazepines (BDEPQ) $(0-27)$ & 2.12 & 4.25 & 2.38 & 4.40 & 1.33 & 3.68 & 1.41 & 3.76 & 0.169 \\
\hline
\end{tabular}


Table 1 (continued)

\begin{tabular}{|c|c|c|c|c|c|c|c|c|c|}
\hline & Mean & SD & Mean & SD & Mean & SD & Mean & SD & $\mathrm{p}$ value \\
\hline \multicolumn{10}{|l|}{ Migration and culture } \\
\hline Health literacy scale & 12.46 & 2.81 & 12.39 & 2.84 & 12.67 & 2.85 & 12.67 & 2.75 & 0.722 \\
\hline Discrimination scale & 17.94 & 7.97 & 18.51 & 8.10 & 18.47 & 9.44 & 15.88 & 6.90 & 0.042 \\
\hline Acculturative stress scale & 2.36 & 2.19 & 2.55 & 2.22 & 1.60 & 1.80 & 1.86 & 2.07 & 0.023 \\
\hline \multirow[t]{2}{*}{ Family conflict scale } & 2.23 & 1.96 & 2.22 & 1.88 & 2.53 & 2.70 & 2.19 & 2.09 & 0.822 \\
\hline & $\mathrm{N}$ & $\%$ & $\mathrm{~N}$ & $\%$ & $\mathrm{~N}$ & $\%$ & $\mathrm{~N}$ & $\%$ & $\mathrm{p}$ value \\
\hline \multicolumn{10}{|l|}{ Trauma exposure } \\
\hline No & 17 & 5 & 10 & 4 & 1 & 7 & 6 & 8 & 0.339 \\
\hline Yes & 324 & 95 & 242 & 96 & 14 & 93 & 68 & 92 & \\
\hline \multicolumn{10}{|l|}{ Citizenship status } \\
\hline Citizen & 189 & 55 & 135 & 54 & 10 & 67 & 44 & 60 & 0.090 \\
\hline Documented immigrants & 41 & 12 & 35 & 14 & 3 & 20 & 3 & 4 & \\
\hline Undocumented immigrants & 104 & 31 & 76 & 30 & 2 & 13 & 26 & 35 & \\
\hline Unknown/No response & 7 & 2 & 6 & 2 & 0 & 0 & 1 & 1 & \\
\hline \multicolumn{10}{|l|}{ Sense of belonging } \\
\hline No & 139 & 41 & 106 & 42 & 10 & 67 & 23 & 31 & 0.003 \\
\hline Yes & 199 & 58 & 144 & 57 & 5 & 33 & 50 & 67 & \\
\hline No response & 3 & 1 & 2 & 1 & 0 & 0 & 1 & 1 & \\
\hline \multicolumn{10}{|l|}{ HIV/STI risk } \\
\hline \multicolumn{10}{|l|}{ Concern for acquiring HIV } \\
\hline A little worried & 238 & 70 & 179 & 71 & 11 & 73 & 48 & 65 & 0.493 \\
\hline Very worried & 100 & 29 & 70 & 28 & 4 & 27 & 26 & 35 & \\
\hline Unknown/no response & 3 & 1 & 3 & 1 & 0 & 0 & 0 & 0 & \\
\hline \multicolumn{10}{|l|}{ Prior HIV test } \\
\hline No & 104 & 31 & 73 & 29 & 4 & 27 & 27 & 37 & 0.494 \\
\hline Yes & 233 & 68 & 176 & 70 & 10 & 67 & 47 & 64 & \\
\hline Unknown/no response & 4 & 1 & 3 & 1 & 1 & 6 & 0 & 0 & \\
\hline \multicolumn{10}{|l|}{ Number of sex partners } \\
\hline$\leq 10$ & 331 & 97 & 244 & 97 & 15 & 100 & 72 & 97 & 0.818 \\
\hline$>10$ & 8 & 2 & 6 & 2 & 0 & 0 & 2 & 3 & \\
\hline Unknown/no response & 2 & 1 & 2 & 1 & 0 & 0 & 0 & 0 & \\
\hline \multicolumn{10}{|l|}{ HIV tested in main partner } \\
\hline No, HIV test not done & 167 & 49 & 122 & 48 & 11 & 73.3 & 34 & 46 & 0.274 \\
\hline Yes, HIV test done & 132 & 39 & 101 & 40 & 2 & 13.3 & 29 & 39 & \\
\hline Unknown & 42 & 12 & 29 & 12 & 2 & 13.3 & 11 & 15 & \\
\hline \multicolumn{10}{|c|}{ History of IDU in main sex partner } \\
\hline Never injected drugs & 335 & 98 & 246 & 98 & 15 & 100 & 74 & 100 & 0.835 \\
\hline Injected drugs & 1 & 0 & 1 & 0 & 0 & 0 & 0 & 0 & \\
\hline Unknown/no response & 5 & 2 & 5 & 2 & 0 & 0 & 0 & 0 & \\
\hline \multicolumn{10}{|c|}{ Sex without a condom in main or casual partner } \\
\hline Use condom & 305 & 89 & 226 & 90 & 13 & 87 & 66 & 89 & 0.839 \\
\hline No condom use & 31 & 9 & 22 & 9 & 2 & 13 & 7 & 10 & \\
\hline Unknown/no response & 5 & 2 & 4 & 1 & 0 & 0 & 1 & 1 & \\
\hline \multicolumn{10}{|c|}{ Anal sex without a condom in main or casual partner } \\
\hline Use condom & 282 & 83 & 207 & 82 & 15 & 100 & 60 & 81 & 0.216 \\
\hline No condom use & 53 & 16 & 40 & 16 & 0 & 0 & 13 & 18 & \\
\hline Unknown/no response & 6 & 2 & 5 & 2 & 0 & 0 & 1 & 1 & \\
\hline
\end{tabular}


Table 1 (continued)

\begin{tabular}{|c|c|c|c|c|c|c|c|c|c|}
\hline & $\mathrm{N}$ & $\%$ & $\mathrm{~N}$ & $\%$ & $\mathrm{~N}$ & $\%$ & $\mathrm{~N}$ & $\%$ & $\mathrm{p}$ value \\
\hline \multicolumn{10}{|c|}{ Sex with a commercial sex worker } \\
\hline No & 278 & 81 & 204 & 81 & 14 & 93 & 60 & 81 & \multirow[t]{3}{*}{0.212} \\
\hline Yes & 58 & 17 & 44 & 18 & 0 & 0 & 14 & 19 & \\
\hline Unknown/no response & 5 & 2 & 4 & 1 & 1 & 7 & 0 & 0 & \\
\hline \multicolumn{10}{|l|}{ History of IDU } \\
\hline No & 330 & 97 & 244 & 97 & 15 & 100 & 71 & 96 & \multirow[t]{3}{*}{0.597} \\
\hline Yes & 9 & 3 & 6 & 3 & 0 & 0 & 3 & 4 & \\
\hline Unknown/no response & 2 & 0 & 2 & 0 & 0 & 0 & 0 & 0 & \\
\hline \multicolumn{10}{|l|}{ History of STI } \\
\hline No & 279 & 82 & 206 & 82 & 11 & 73 & 62 & 84 & \multirow[t]{2}{*}{0.632} \\
\hline Yes & 62 & 18 & 46 & 18 & 4 & 27 & 12 & 16 & \\
\hline
\end{tabular}

For continuous variables, mean and SD are reported. For categorical variables, absolute and percentage for each category is reported

STI sexually transmitted infection, $S D$ standard deviation, $P H Q$ Patient Health Questionnaire, GAD Generalized Anxiety Disorder, PTSD posttraumatic stress disorder, $P C L$ PTSD checklist, DAST Drug Abuse Screening Test, AUDIT Alcohol Use Disorders Identification Test, $B D E P Q$ Benzodiazepene Dependence Questionnaire, IDU injection drug use

the majority $(n=61,82 \%)$ were from South America. There were also significant differences in test acceptance, decline, and LTFU by study site (Boston, Madrid and Barcelona) $(\mathrm{p}=0.003)$. Of the 74 participants who were LTFU, $70 \%$ $(\mathrm{n}=52)$ were recruited in Barcelona. In those who accepted testing, 24\% $(n=61)$ had a college degree or higher, compared with $7 \%(n=1)$ of those who declined, and $5 \%(n=4)$ of those LTFU ( $\mathrm{p}=0.006)$ (Table 2).

There was no statistically significant difference in access to services or mental health outcomes between groups.

In the univariate analysis, we found significant differences in test acceptance by sense of belonging, everyday discrimination, and acculturative stress. A report of no sense of belonging to either the Latin country of origin or the US/Spain was less common in those who accepted testing $(n=106,42 \%)$ and those LTFU $(n=23,31 \%)$ compared with those who declined $(n=10,67 \%)(p=0.003)$. Those who were LTFU reported a lower mean discrimination score, 15.88 ( $\mathrm{SD} \pm 6.90)$, compared with those who accepted testing, 18.51 ( $\mathrm{SD} \pm 8.10)$, and those who declined testing, 18.47 ( $\mathrm{SD} \pm 9.44),(\mathrm{p}=0.042)$. Acculturative stress was also higher in those who accepted testing, 2.55 ( $\mathrm{SD} \pm 2.22$ ), compared with $1.60(\mathrm{SD} \pm 1.80)$ in those who declined and $1.86(\mathrm{SD} \pm 2.07)$ in those LTFU $(\mathrm{p}=0.023)$.

We did not find a statistically significant difference in HIV/STI risk factors based on variables that assessed knowledge and behavior between these groups.

In the multivariable model, the odds of test decline were lower when recruitment occurred from participants in a community agency or personal referral compared with a primary care site or emergency room (OR 0.49 [95\% CI $0.26-0.92]$ ) and when the participant reported that the main sex partner had an HIV test in the past year compared with when the partner did not (OR 0.14 [95\% CI 0.04-0.57]). A history of a STI increased the odds of test decline (OR 2.12 [95\% CI 1.20-3.76]) when contrasted with those without a history of STI. Composite substance use score was lower (OR 0.99 [95\% CI 0.98-0.99]) in those who declined testing, but the difference was minimal. Higher health literacy score increased the odds of test decline (OR 1.10 [95\% CI 1.00-1.21]). Pariticipants recuited in Madrid were associated with lower odds of test decline as compared to those from Boston. There was no statistically significant difference in those who declined compared with those who accepted HIV/STI testing by participant's age, gender, educational status, citizenship status, intervention assignment, composite mental health score, everyday discrimination, family conflict, or concern for acquiring HIV.

The odds of being LTFU were lower in those age 35 years and older compared with participants ages 18-34 years (OR 0.37 [95\% CI 0.18-0.74]), females compared with males (OR 0.70 [95\% CI 0.63-0.77]), and those with a college degree or higher compared with less than high school diploma (OR 0.13 [95\% CI 0.10-0.17]). Higher reported everyday descrimination scores lowered the odds of LTFU (OR $=0.94$ [95\% CI 0.88-0.99]). An increased odds of LTFU were found in those who reported being very or extremely concerned about acquiring HIV compared with those who reported no concern (OR 1.53 [95\% CI 1.25-1.87]). Participants who reported that their main sex partner had an HIV test in the past year had a higher odds of LTFU than those whose partners did not (OR 1.28 [95\% CI 1.21-1.36]). The association was similar in those who reported that the HIV testing status of their sex partner was unknown. Finally, compared to Boston, participants recruited from Madrid had lower odds of being LTFU (OR 0.78 [95\% CI 0.62-0.98]) whereas those from Barcelona were more likely to be LTFU (OR 2.56 [95\% CI 1.56-4.19]). 
Table 2 Odds ratios and 95\% confidence intervals from a multinomial logistic regression for the association between the covariates and HIV/STI test acceptance in a multi-site cohort of Latino immigrants with co-occurring substance use and mental health problems

\begin{tabular}{|c|c|c|}
\hline Characteristic & Declined & Lost to follow-up \\
\hline \multicolumn{3}{|l|}{ Age (years) } \\
\hline $18-34$ & 1.00 & 1.00 \\
\hline $35+$ & $0.61(0.30,1.23)$ & $0.37(0.18,0.74)^{* *}$ \\
\hline \multicolumn{3}{|l|}{ Gender } \\
\hline Male & 1.00 & 1.00 \\
\hline Female & $0.9(0.26,3.09)$ & $0.70(0.63,0.77)^{* * *}$ \\
\hline \multicolumn{3}{|l|}{ Education status } \\
\hline Less than high school & 1.00 & 1.00 \\
\hline High school diploma and vocational & $0.98(0.49,1.94)$ & $0.96(0.46,1.99)$ \\
\hline College degree and higher & $0.24(0.01,6.65)$ & $0.13(0.10,0.17)^{* * *}$ \\
\hline \multicolumn{3}{|l|}{ Citizenship status } \\
\hline Citizen & 1.00 & 1.00 \\
\hline Non-citizen & $1.38(0.90,2.14)$ & $1.23(0.93,1.64)$ \\
\hline \multicolumn{3}{|l|}{ Recruitment agency } \\
\hline Primary care/emergency room & 1.00 & 1.00 \\
\hline Community agency/referral & $0.49(0.26,0.92)^{*}$ & $0.74(0.45,1.20)$ \\
\hline Intervention indicator & $1.17(0.52,2.62)$ & $1.3(0.61,2.75)$ \\
\hline Composite mental health score (PHQ, GAD, PCL) & $1.00(0.95,1.05)$ & $1.01(0.98,1.03)$ \\
\hline Composite substance use score (DAST, AUDIT, BD) & $0.99(0.98,0.99)^{* *}$ & $1.01(1.00,1.02)$ \\
\hline Health literacy scale & $1.10(1.00,1.21)^{*}$ & $0.96(0.78,1.17)$ \\
\hline Discrimination scale & $0.99(0.97,1.01)$ & $0.94(0.88,0.99) *$ \\
\hline Family conflict scale & $1.12(0.77,1.62)$ & $1.05(0.80,1.37)$ \\
\hline \multicolumn{3}{|l|}{ Concern for HIV } \\
\hline Not at all & 1.00 & 1.00 \\
\hline Very/extremely worried & $0.93(0.13,6.44)$ & $1.53(1.25,1.87)^{* * *}$ \\
\hline \multicolumn{3}{|l|}{ Main partner had HIV test } \\
\hline No & 1.00 & 1.00 \\
\hline Yes & $0.14(0.04,0.57)^{* *}$ & $1.28(1.21,1.36)^{* * *}$ \\
\hline Unknown & $0.75(0.26,2.14)$ & $1.65(1.16,2.33)^{* *}$ \\
\hline \multicolumn{3}{|l|}{ History of STI } \\
\hline No & 1.00 & 1.00 \\
\hline Yes & $2.12(1.20,3.76)^{*}$ & $0.88(0.68,1.15)$ \\
\hline \multicolumn{3}{|l|}{ Study site } \\
\hline Boston & 1.00 & 1.00 \\
\hline Madrid & $0.15(0.13,0.18)^{* * *}$ & $0.78(0.62,0.98) *$ \\
\hline Barcelona & $0.46(0.20,1.03)$ & $2.56(1.56,4.19)^{* * *}$ \\
\hline
\end{tabular}

\section{Discussion}

International goals to reduce HIV transmission and improve treatment outcomes hinge upon the engagement of key populations. For Latino immigrants in Spain and the US with co-occurring substance use and mental health problems, we found that HIV/STI test acceptance was high, as 74\% accepted testing through a behavioral health study and only $4 \%$ declined. Approximately one-fifth of the cohort dropped out or were LTFU before HIV/STI testing was offered. Given the acceptability of HIV/STI testing, these data suggest the importance of integrating HIV/STI testing in routine health or outreach visits, including behavioral health encounters.

Individuals recruited from community settings had a $51 \%$ reduction in the odds of HIV/STI test decline and individuals whose main sex partner had a prior HIV test had a $86 \%$ lower odds of test refusal. A possible explanation for greater test acceptance in these scenarios may relate to a number of psychological factors, such as participants' lower expectation for a positive test result, decreased perceptions of HIV-related stigma, and a positive perception of the benefits of testing $[1,70,71]$. The fact that those participants 
reporting a higher concern for having HIV were more likely to be LTFU and did not receive HIV/STI testing may imply greater ambivalence towards a positive test result in this group [72, 73].

LTFU was more likely in those who were younger age, males, less educated and extremely worried about acquiring HIV. These data characterize a potential vulnerable pool not willing to engage in HIV/STI testing. This group may require tailored interventions, such as through youth friendly internet-based formats, to successfully promote HIV testing [74]. HIV self-testing may improve testing acceptability compared to community or health facilitybased testing by addresssing concerns about privacy, stigma, and access to health services [75-78]. LTFU was also more substantial in the Barcelona site, which had twice the number of participants as Madrid and Boston. This finding emphasizes the challenge of tracking patients as the population for follow-up increases and resources are limited. The higher attrition in Barcelona, as compared to other sites, was not due to the random assignment of the study condition as assignment of the study condition did not predict LTFU.

Higher everyday discrimination decreased the odds of LTFU. This finding may have occurred because of how the study was designed and delivered specifically to Latino immigrants. Study visits were conducted by Spanish-speaking program staff. Participants selected the timing and location, in person or by telephone, of study visits. Missed visits were followed up by phone calls, letters, and home visits. Based on our findings, addressing perceived discrimination may be a key component in retaining Latino immigrants in services such that individuals can access HIV/STI testing. Interventions in Latino churches and with community health workers has shown promise in reducing HIV-related stigma and improving intention for HIV testing [79]. Furthermore, increased social support and knowing others with HIV predicted HIV/STI test acceptance in Colombian men who have sex with men [80].

This study had several limitations. Despite substantial efforts to track patients and the options for home-based and telephone study visits, $22 \%$ of the cohort was LTFU and their HIV/STI testing responses are unknown. Participants may not have reported the accurate status of the main sex partner's HIV testing history due to social desirability or reluctance in disclosing this information [81]. Participants agreed to take part in a behavioral counseling intervention for mental health and substance use. Therefore, the rate of HIV/STI test acceptance may not generalize to individuals who refused study participation.

Addressing determinants of HIV test acceptance as well as attrition from services for Latino immigrants with cooccurring substance use and mental health problems may help close the gap in key disparities in HIV outcomes for
Latinos. Prior evidence suggests that once diagnosed, response to HIV treatment and viral suppression for HIVinfected Latinos may be no different than their native-born counterparts in the US and Europe [82-84]. The opportunity for HIV treatment success in Latinos further underscores the importance of prompt HIV diagnosis and linkage to care. Delivery of HIV testing in routine settings, including mental health, may improve attainment of national guidelines to integrate HIV testing in preventative health care [85, 86], and lessen ambivalence to HIV testing in Latino immigrants, a growing population for whom there are limited tailored HIV interventions.

Acknowledgements The work was supported by the National Institutes Health (National Institute of Mental Health grant K23 MH100978 and National Institute on Drug Abuse grant and supplement R01 DA034952), and a CFAR ADELANTE award funded by the NIH-funded Centers for AIDS Research (P30AI050409 and P30AI117970) and the U.S. National Institutes of Health. The funders had no role in study design, data collection and analysis, decision to publish, or preparation of the manuscript. The content is solely the responsibility of the authors and does not necessarily represent the official views of Harvard University, Harvard Medical School and its affiliated academic health care centers, or the National Institutes of Health.

Authors Contributions All authors have contributed significantly to the work, have seen and approved of this manuscript. Author contributions include formulation of the research question (Levison, Alegría, ElBassel), design of the analytic plan (Levison, Alegría, Markle, Wang), data collection (Fuentes, Albarracín, Cellerino, Markle, Alegría), data analysis (Wang, Levison, Alegría), manuscript preparation (Levison, Alegría, Markle), and critical editing (Levison, Alegría, Wang, Markle, Mejia, Tarbox, El-Bassel). The contents of this article have not been published, and the paper is not under review elsewhere for publication.

\section{Compliance with Ethical Standards}

Conflict of interest All authors have declared that no competing interests exist.

Ethical Approval All procedures performed in studies involving human participants were in accordance with the ethical standards of the institutional and/or national research committee and with the 1964 Helsinki declaration and with the 1964 Helsinki declaration and its later amendments or comparable ethical standards.

Informed Consent Informed consent was obtained from all individual participants included in the study.

\section{References}

1. Dailey AF, Hoots BE, Hall HI, Song R, Hayes D, Fulton P Jr, et al. Vital signs: human immunodeficiency virus testing and diagnosis delays-United States. MMWR Morb Mortal Wkly Rep. 2017;66(47):1300-6.

2. Nunez O, Hernando V, Diaz A. Estimating the number of people living with HIV and the undiagnosed fraction in Spain in 2013. AIDS. 2018;32:2573. 
3. Sapsirisavat V, Phanuphak N, Keadpudsa S, Egan JE, Pussadee $\mathrm{K}$, Klaytong P, et al. Psychosocial and behavioral characteristics of high-risk men who have sex with men (MSM) of unknown HIV positive serostatus in Bangkok, Thailand. AIDS Behav. 2016;20(Suppl 3):386-97.

4. Zea MC, Reisen CA, del Rio-Gonzalez AM, Bianchi FT, Ramirez-Valles J, Poppen PJ. HIV prevalence and awareness of positive serostatus among men who have sex with men and transgender women in Bogota, Colombia. Am J Public Health. 2015;105(8):1588-95.

5. Reisen CA, Zea MC, Bianchi FT, Poppen PJ. Characteristics of Latino MSM who have sex in public settings. AIDS Care. 2011;23(4):456-9.

6. Joint United Nations Program on HIV/AIDS (UNAIDS). 90-9090 An ambitious treatment target to help end the AIDS epidemic. 2014. http://www.unaids.org/sites/default/files/media_asset/9090-90_en_0.pdf. Accessed 26 June 2018.

7. World Bank. International migrant stock, total. http://data.world bank.org/indicator/SM.POP.TOTL. Accessed 21 August 2017.

8. The World Bank. International migration at all-time high. http:// www.worldbank.org/en/news/press-release/2015/12/18/internatio nal-migrants-and-remittances-continue-to-grow-as-people-searc h-for-better-opportunities-new-report-finds. Accessed 25 July 2017.

9. Pew Research Center. Statistical portrait of Hispanics in the United States. http://www.pewhispanic.org/2016/04/19/statistica 1-portrait-of-hispanics-in-the-united-states/. Accessed 17 October 2018.

10. Instituto Nacional de Estadística. Estadística del Padrón continuo 01/01/18. http://www.ine.es/dyngs/INEbase/es/operacion. $\mathrm{htm} ? \mathrm{c}=$ Estadistica_C\&cid $=1254736177012 \&$ menu $=$ resultados $\& \operatorname{secc}=1254736195557 \& \mathrm{idp}=1254734710990$. Accessed 17 October 2018

11. Poncini, H. La población extranjera en España aumenta por primera vez desde la crisis. El Pais. 2018. https://elpais.com/polit ica/2018/04/24/actualidad/1524564519_812661.html. Accessed 17 October 2018.

12. UNAIDS. HIV prevention among key populations. 2016. http:// www.unaids.org/en/resources/presscentre/featurestories/2016/ november/20161121_keypops. Accessed 25 July 2017.

13. UNAIDS. Country progress report 2016. http://www.unaids.org/ en/regionscountries/countries/spain. Accessed 31 Jan 2018.

14. Centers for Disease Control. HIV among hispanics/latinos. https ://www.cdc.gov/hiv/group/racialethnic/hispaniclatinos/. Accessed 8 March 2018.

15. Zhang X, Rhoads N, Rangel MG, Hovell MF, Magis-Rodriguez C, Sipan CL, et al. Understanding the impact of migration on HIV risk: an analysis of Mexican migrants' sexual practices, partners, and contexts by migration phase. AIDS Behav. 2017;21(3):935-48.

16. Weine SM, Kashuba AB. Labor migration and HIV risk: a systematic review of the literature. AIDS Behav. 2012;16(6):1605-21.

17. Rhodes SD, McCoy TP. Condom use among immigrant Latino sexual minorities: multilevel analysis after respondent-driven sampling. AIDS Educ Prev. 2015;27(1):27-43.

18. Kutner BA, Nelson KM, Simoni JM, Sauceda JA, Wiebe JS. Factors associated with sexual risk of HIV Transmission among hivpositive latino men who have sex with men on the U.S.-Mexico Border. AIDS Behav. 2017;21(3):923-34.

19. Poppen PJ, Reisen CA, Zea MC, Bianchi FT, Echeverry JJ. Predictors of unprotected anal intercourse among HIV-positive Latino gay and bisexual men. AIDS Behav. 2004;8(4):379-89.

20. Campbell AN, Tross S, Calsyn DA. Substance use disorders and HIV/AIDS prevention and treatment intervention: research and practice considerations. Soc Work Public Health. 2013;28(3-4):333-48.
21. Gray KM, Valverde EE, Tang T, Siddiqi AE, Hall HI. Diagnoses and prevalence of HIV infection among hispanics or latinosUnited States, 2008-2013. MMWR Morb Mortal Wkly Rep. 2015;64(39):1097-103.

22. Trepka MJ, Fennie KP, Sheehan DM, Lutfi K, Maddox L, Lieb S. Late HIV diagnosis: differences by rural/urban residence, Florida, 2007-2011. AIDS Patient Care STDS. 2014;28(4):188-97.

23. Levison JH, Levinson JK, Alegria M. A critical review and commentary on the challenges in engaging HIV-infected latinos in the continuum of HIV care. AIDS Behav. 2018;22(8):2500-12.

24. Dennis AM, Wheeler JB, Valera E, Hightow-Weidman L, Napravnik S, Swygard $\mathrm{H}$, et al. HIV risk behaviors and sociodemographic features of HIV-infected Latinos residing in a new Latino settlement area in the Southeastern United States. AIDS Care. 2013;25(10):1298-307.

25. Navaza B, Abarca B, Bisoffi F, Pool R, Roura M. Provider-initiated HIV testing for migrants in Spain: a qualitative study with health care workers and foreign-born sexual minorities. PLoS ONE. 2016;11(2):e0150223.

26. Hernando V, Arco DA, Alejos B, Monge S, Amato-Gauci AJ, Noori T, et al. HIV infection in migrant populations in the European Union and European Economic Area in 2007-2012: an epidemic on the move. J Acquir Immune Defic Syndr. 2015;70(2):204-11.

27. Monge S, Alejos B, Dronda F, Del Romero J, Iribarren JA, Pulido $\mathrm{F}$, et al. Inequalities in HIV disease management and progression in migrants from Latin America and sub-Saharan Africa living in Spain. HIV Med. 2013;14(5):273-83.

28. Galvan FH, Bogart LM, Klein DJ, Wagner GJ, Chen YT. Medical mistrust as a key mediator in the association between perceived discrimination and adherence to antiretroviral therapy among HIV-positive Latino men. J Behav Med. 2017;40(5):784-93.

29. Gilbert PA, Rhodes SD. HIV testing among immigrant sexual and gender minority Latinos in a US region with little historical Latino presence. AIDS Patient Care STDS. 2013;27(11):628-36.

30. Zambrana RE, Cornelius LJ, Boykin SS, Lopez DS. Latinas and HIV/AIDS risk factors: implications for harm reduction strategies. Am J Public Health. 2004;94(7):1152-8.

31. Lopez-Quintero C, Shtarkshall R, Neumark YD. Barriers to HIV-testing among Hispanics in the United States: analysis of the National Health Interview Survey, 2000. AIDS Patient Care STDS. 2005;19(10):672-83.

32. Kinsler JJ, Lee SJ, Sayles JN, Newman PA, Diamant A, Cunningham W. The impact of acculturation on utilization of HIV prevention services and access to care among an at-risk Hispanic population. J Health Care Poor Underserved. 2009;20(4):996-1011.

33. Martinez-Donate AP, Zhang X, Rangel MG, Hovell M, GonzalezFagoaga JE, Magis-Rodriguez C, et al. Does acculturative stress influence immigrant sexual HIV risk and HIV testing behavior? Evidence from a survey of male Mexican migrants. J Racial Ethn Health Disparities. 2017;5:798.

34. Jardin C, Garey L, Sharp C, Zvolensky MJ. Acculturative stress and risky sexual behavior: the roles of sexual compulsivity and negative affect. Behav Modif. 2016;40(1-2):97-119.

35. Senn TE, Carey MP. HIV testing among individuals with a severe mental illness: review, suggestions for research and clinical implications. Psychol Med. 2009;39:355-63.

36. Karamouzian M, Shoveller J, Dong H, Gilbert M, Kerr T, DeBeck K. Perceived devaluation and STI testing uptake among a cohort of street-involved youth in a Canadian setting. Arch Sex Behav. 2017;46(7):2165-72.

37. Blank MB, Himelhoch SS, Balaji AB, Metzger DS, Dixon LB, Rose CE, et al. A multisite study of the prevalence of HIV with rapid testing in mental health settings. Am J Public Health. 2014;104(12):2377-84. 
38. De Leon J, Rendon DM, Baca-Garcia E, Aizpuru F, GonzalezPinto A, Anitua C, et al. Association between smoking and alcohol use in the general population: stable and unstable odds ratios across two years in two different countries. Alcohol Alcohol. 2007;42(3):252-7.

39. Baca-Garcia E, Perez-Rodriguez MM, Basurte-Villamor I, SaizRuiz J, Leiva-Murillo JM, de Prado-Cumplido M, et al. Using data mining to explore complex clinical decisions: a study of hospitalization after a suicide attempt. J Clin Psychiatry. 2006;67(7):1124-32.

40. Qureshi A, Collazos F. The intercultural and interracial therapeutic relationship: challenges and recommendations. Int Rev Psychiatry. 2011;23(1):10-9.

41. Chavez LM, Shrout PE, Wang Y, Collazos F, Carmona R, Alegria M. Evaluation of the AC-OK mental health and substance abuse screening measure in an international sample of Latino immigrants. Drug Alcohol Depend. 2017;180:121-8.

42. Cherry AL, Dillon ME. The AC-OK cooccurring screen: reliability, convergent validity, sensitivity, and specificity. J Addict. 2013;2013:573906.

43. Paykel ES, Hallowell C, Dressler DM, Shapiro DL, Weissman MM. Treatment of suicide attempters. A descriptive study. Arch Gen Psychiatry. 1974;31(4):487-91.

44. Alegria M, Falgas-Bague I, Collazos F, Carmona Camacho R, Lapatin Markle S, Wang Y, et al. Evaluation of the Integrated Intervention for Dual Problems and Early Action Among Latino Immigrants With Co-occurring Mental Health and Substance Misuse Symptoms: A Randomized Clinical Trial. JAMA Netw Open. 2019;2:e186927.

45. El-Bassel N, Witte SS, Gilbert L, Wu E, Chang M, Hill J, et al. The efficacy of a relationship-based HIV/STD prevention program for heterosexual couples. Am J Public Health. 2003;93(6):963-9.

46. Kamb ML, Fishbein M, Douglas JM Jr, Rhodes F, Rogers J, Bolan $\mathrm{G}$, et al. Efficacy of risk-reduction counseling to prevent human immunodeficiency virus and sexually transmitted diseases: a randomized controlled trial. Project RESPECT Study Group. JAMA. 1998;280(13):1161-7.

47. Kroenke K, Spitzer RL, Williams JB. The PHQ-9: validity of a brief depression severity measure. J Gen Intern Med. 2001;16(9):606-13.

48. Spitzer RL, Kroenke K, Williams JB, Lowe B. A brief measure for assessing generalized anxiety disorder: the GAD-7. Arch Intern Med. 2006;166(10):1092-7.

49. Blevins CA, Weathers FW, Davis MT, Witte TK, Domino JL. The posttraumatic stress disorder checklist for DSM-5 (PCL-5): development and initial psychometric evaluation. J Trauma Stress. 2015;28(6):489-98.

50. Yudko E, Lozhkina O, Fouts A. A comprehensive review of the psychometric properties of the drug abuse screening test. J Subst Abuse Treat. 2007;32(2):189-98.

51. Babor TF, Higgins-Biddle JC, Saunders JB, Monteiro MG. AUDIT: the alcohol use disorders indentification test: guidelines for use in primary care. 2nd ed. Geneva: World Health Organization, Department of Mental Health and Substance Dependence; 2001.

52. Baillie AJ, Mattick RP. The benzodiazepine dependence questionnaire: development, reliability and validity. Br J Psychiatry. 1996;169(3):276-81.

53. Schnurr PP, Vieilhauer MJ, Weathers F, Findler M. The brief trauma questionnaire. White River Junction: National Center for PTSD; 1999.

54. Schnurr PP, Spiro A III, Vielhauer MJ, Findler MN, Hamblen JL. Trauma in the lives of older men: findings from the normative aging study. J Clin Geropsych. 2002;8:175-87.
55. Cervantes RC, Padilla AM, de Snyder NS. The Hispanic stress inventory: a culturally relevant approach to psychosocial assessment. Psychol Assess: J Consult Clin Psychol. 1991;3(3):438.

56. Alegria M, Jackson JS, Kessler, RC. Collaborative Psychiatric Epidemiology Surveys (CPES), 2001-2003 [United States]. NCS-R Specific Documentation (ICPSR 20240). Inter-University Consortium for Political and Social Research: Ann Arbor, Michigan. Ann Arbor, MI: Inter-University Consortium for Political and Social Research. 2001. http://www.icpsr.umich.edu/cgibin/file.

57. Morris NS, MacLean CD, Chew LD, Littenberg B. The single item literacy screener: evaluation of a brief instrument to identify limited reading ability. BMC Fam Pract. 2006;7:21.

58. Williams DR, Yan Y, Jackson JS, Anderson NB. Racial differences in physical and mental health: socio-economic status, stress and discrimination. J Health Psychol. 1997;2(3):335-51.

59. Steidel AGL, Contreras JM. A new familism scale for use with latino populations. Hispanic J Behav Sci. 2003;25(3):312-30.

60. Cervantes RC, Padilla AM, Amado M, de Snyder NS. Reliability and validity of the hispanic stress inventory. Hispanic J Behav Sci. 1990;12:76-82.

61. National Institute of Drug Abuse. Seek, Test, Treat and Retain for Vulnerable Populations: Data Harmonization Measure. 2013. https://www.drugabuse.gov/sites/default/files/sttrfiles/HIV_Risk_ BehaviorsV.pdf. Accessed 13 March 2018.

62. Fisher JD, Fisher WA, Cornman DH, Amico RK, Bryan A, Friedland GH. Clinician-delivered intervention during routine clinical care reduces unprotected sexual behavior among HIV-infected patients. J Acquir Immune Defic Syndr. 2006;41(1):44-52.

63. Jones HE, Berkman ND, Kline TL, Ellerson RM, Browne FA, Poulton W, et al. Initial feasibility of a woman-focused intervention for pregnant African-American women. Int J Pediatr. 2011;2011:389285.

64. Haukoos JS, Lyons MS, Lindsell CJ, Hopkins E, Bender B, Rothman RE, et al. Derivation and validation of the denver human immunodeficiency virus (HIV) risk score for targeted HIV screening. Am J Epidemiol. 2012;175(8):838-46.

65. Hoenigl M, Weibel N, Mehta SR, Anderson CM, Jenks J, Green $\mathrm{N}$, et al. Development and validation of the San Diego early test score to predict acute and early HIV infection risk in men who have sex with men. Clin Infect Dis. 2015;61(3):468-75.

66. Datta SD, Sternberg M, Johnson RE, Berman S, Papp JR, McQuillan G, et al. Gonorrhea and chlamydia in the United States among persons 14 to 39 years of age, 1999 to 2002. Ann Intern Med. 2007;147(2):89-96.

67. Hosmer DW, Lemeshow S. Applied logistic regression. 2nd ed. New York: Wiley; 2000. p. 373.

68. Heinze G, Schemper M. A solution to the problem of separation in logistic regression. Stat Med. 2002;21(16):2409-19.

69. StataCorp. Stata Statistical Software: Release 14. College Station: StataCorp LP; 2015.

70. Evangeli M, Pady K, Wroe AL. Which psychological factors are related to HIV testing? A quantitative systematic review of global studies. AIDS Behav. 2016;20(4):880-918.

71. Ford CL, Wallace SP, Newman PA, Lee SJ, Cunningham WE. Belief in AIDS-related conspiracy theories and mistrust in the government: relationship with HIV testing among at-risk older adults. Gerontologist. 2013;53(6):973-84.

72. Gu J, Lau JT, Tsui H. Psychological factors in association with uptake of voluntary counselling and testing for HIV among men who have sex with men in Hong Kong. Public Health. 2011;125(5):275-82.

73. Flowers P, Knussen C, Li J, McDaid L. Has testing been normalized? An analysis of changes in barriers to HIV testing among men who have sex with men between 2000 and 2010 in Scotland, UK. HIV Med. 2013;14(2):92-8. 
74. Cordova D, Alers-Rojas F, Lua FM, Bauermeister J, Nurenberg $\mathrm{R}$, Ovadje L, et al. The usability and acceptability of an adolescent mHealth HIV/STI and drug abuse preventive intervention in primary care. Behav Med. 2016;44:1-12.

75. Chiu CJ, Young SD. Correlates of requesting home HIV selftesting kits on online social networks among African-American and latino men who have sex with men. AIDS Care. 2016;28(3):289-93.

76. Murray A, Gaul Z, Sutton MY, Nanin J. "We hide..." perceptions of HIV risk among black and Latino MSM in New York City. Am J Mens Health. 2017;12:180.

77. Young SD, Daniels J, Chiu CJ, Bolan RK, Flynn RP, Kwok J, et al. Acceptability of using electronic vending machines to deliver oral rapid HIV self-testing kits: a qualitative study. PLoS ONE. 2014;9(7):e103790.

78. Pando MA, Dolezal C, Marone RO, Barreda V, Carballo-Dieguez A, Avila MM, et al. High acceptability of rapid HIV self-testing among a diverse sample of MSM from Buenos Aires, Argentina. PLoS ONE. 2017;12(7):e0180361.

79. Derose KP, Bogart LM, Kanouse DE, Felton A, Collins DO, Mata MA, et al. An intervention to reduce HIV-related stigma in partnership with African American and Latino churches. AIDS Educ Prev. 2014;26(1):28-42.

80. Reisen CA, Zea MC, Bianchi FT, Poppen PJ, del Rio Gonzalez AM, Romero RA, et al. HIV testing among MSM in Bogota, Colombia: the role of structural and individual characteristics. AIDS Educ Prev. 2014;26(4):328-44.

81. Holloway IW, Padilla MB, Willner L, Guilamo-Ramos V. Effects of minority stress processes on the mental health of Latino men who have sex with men and women: a qualitative study. Arch Sex Behav. 2015;44(7):2087-97.

82. Levison JH, Regan S, Khan I, Freedberg KA. Foreign-born status as a predictor of engagement in HIV care in a large US metropolitan health system. AIDS Care. 2016;29:1-8.

83. Poon KK, Dang BN, Davila JA, Hartman C, Giordano TP. Treatment outcomes in undocumented Hispanic immigrants with HIV infection. PLoS ONE. 2013;8(3):e60022.

84. Thierfelder C, Weber R, Elzi L, Furrer H, Cavassini M, Calmy A, et al. Participation, characteristics and retention rates of HIVpositive immigrants in the Swiss HIV Cohort Study. HIV Med. 2012;13(2):118-26.

85. Branson BM, Handsfield HH, Lampe MA, Janssen RS, Taylor AW, Lyss SB, et al. Revised recommendations for HIV testing of adults, adolescents, and pregnant women in health-care settings. MMWR Recommendations and reports Morbidity and mortality weekly report Recommendations and reports. Centers for Disease Control. 2006;55:1-17.

86. Moyer VA, U.S. Preventive Services Task Force. Screening for HIV: U.S. preventive services task force recommendation statement. Ann Intern Med. 2013;159(1):51-60.

Publisher's Note Springer Nature remains neutral with regard to jurisdictional claims in published maps and institutional affiliations. 